\title{
Trends in the Efficiency of Federal Reserve Check Processing Operations
}

\author{
David C. Wheelock and Paul W. Wilson
}

I

n 2000, U.S. consumers, businesses, and government entities made some 71.5 billion non-cash payments, with a value of approximately $\$ 46.6$ trillion. Paper checks accounted for about 60 percent of the total number of non-cash retail payments, with credit and debit cards and automatic clearinghouse $(\mathrm{ACH})$ payments making up the remainder. Approximately 29 percent of checks were deposited or cashed at the same depository institution on which they were drawn, so-called "on us" checks. Of the remaining 71 percent, a high percentage were processed by the Federal Reserve System, moving physically through one or more Fed check processing facilities, which are located in Federal Reserve Banks, Branches, and dedicated processing offices. ${ }^{1}$ In 2002 , the Federal Reserve processed some 16.6 billion checks, generating $\$ 759$ million in revenue and $\$ 744.3$ million in expenses for the System (Board of Governors of the Federal Reserve System, 2002, pp. 128, 139).

Both the number of checks written and the number processed by the Federal Reserve have been declining since the late 1990s, as payments are increasingly made electronically. Survey data show a decline in the number of checks paid from 49.5 billion in 1995 to 42.5 billion in 2000, the last year for which data are available, while the number of electronic payments increased by 14.2 billion items. Between 1995 and 2000, the share of total non-cash payments made by checks declined from 77 percent to 60 percent (Gerdes and Walton, 2002). The number of checks cleared by the Federal Reserve has also been declining. The Fed's processing volume peaked

1 These data are based on comprehensive surveys of payments activity sponsored by the Federal Reserve. See Gerdes and Walton (2002). in 1992 at over 19 billion checks. New settlement rules adopted in 1994 caused the number of checks processed by the Fed to fall sharply, to a low of 15.5 billion in $1995 .^{2}$ Although the Fed's processing volume rose annually between 1995 and 1999, in 1999 the Fed handled 17.1 billion checks and volume has since been declining steadily.

The Monetary Control Act of 1980 requires the Federal Reserve to charge fees for providing payments services, including check processing, to cover (i) the Fed's expenses and (ii) imputed taxes and profits that would be earned by private firms providing similar services. Because of declining volume, the Federal Reserve recently determined that it must reduce the number of its offices that process checks to remain in compliance with the cost-recovery requirements of the Monetary Control Act.

Legislation taking effect in October 2004 has the potential to reduce further the volume of paper checks processed by the Federal Reserve. The Check Clearing for the 21st Century Act, or Check 21, creates a new negotiable instrument, called a substitute check. Substitute checks are printed reproductions made from digital images of the original paper checks and are the legal equivalent of the original checks. The legal status of substitute checks will facilitate the truncation of checks and greater use of electronic check processing. It will thus replace some of the physical movement of paper checks from the banks where checks are cashed or deposited to the banks on which they are drawn or returned.

2 Rules were implemented through the Fed's Regulation CC on January 3, 1994, that enabled collecting banks to receive same-day settlement by presenting checks directly to paying banks by 8:00 a.m. Checks cleared by the Fed declined 13.3 percent in 1994, as banks found it advantageous under the new rules to switch some clearing of checks to private clearinghouses.

David C. Wheelock is an assistant vice president and economist at the Federal Reserve Bank of St. Louis. Paul W. Wilson is a professor of economics at the University of Texas at Austin; this research was carried out while Wilson was a visiting scholar at the Federal Reserve Bank of St. Louis. The authors thank Tom Garrett and Alton Gilbert for comments on a previous version of this article. Heidi L. Beyer, Joshua Ulrich, and Neil Wiggins provided research assistance.

Federal Reserve Bank of St. Louis Review, September/October 2004, 86(5), pp. 7-19

( 2004 , The Federal Reserve Bank of St. Louis. 
The Monetary Control Act sought to use market discipline to improve the efficiency with which the Fed provides payments services. If the demand for its paper check processing continues to fall, the Fed will face intensified pressures to reduce its costs if it is to remain in compliance with the Act. This article investigates patterns in the efficiency of Fed check processing operations over time, and it introduces a new technique for estimating efficiency that overcomes estimation problems inherent in methods used previously to examine the efficiency of Fed payments services.

The next section describes the efficiency concept used in this article. We then describe the processing of checks by Federal Reserve offices and discuss our empirical model and data. Subsequent sections discuss alternative ways of estimating efficiency, focusing on the nonparametric data envelopment analysis (DEA) and order- $m$ estimators, and present estimation results and conclusions.

\section{INPUT TECHNICAL EFFICIENCY}

This article examines changes in the technical efficiency of Federal Reserve check offices over time. A decisionmaking unit (a Fed check office in our context) is input-inefficient if it uses more input to produce a given quantity of output than the existing technology requires. For production processes involving a single input, input-technical inefficiency is measured simply as the ratio of input actually used to the minimum feasible input amount required to produce a given amount of output. For processes involving multiple inputs, inefficiency is measured by the proportionate overuse of all inputs.

Inefficiency can also be measured by the extent to which an office produces less than the technically feasible amount of output from given amounts of input. The output of a Fed check office (e.g., the number of checks processed) is largely outside the office's control, however, at least in the short run. Hence, we focus on input technical efficiency, rather than output technical efficiency. Although technical efficiency is among the most frequently investigated types of efficiency, a comprehensive analysis of Fed check offices, or any other type of organization, would require examination of a variety of performance measures. ${ }^{3}$

\footnotetext{
3 Other measures of efficiency include allocative efficiency, which takes account of input prices to determine the efficient mix of inputs, and scale efficiency, which refers to operation at efficient scale. Other
}

Thus far, evidence on the impact of the Monetary Control Act on the Fed's efficiency in providing payments services has been mixed. That evidence, which is discussed more fully in Gilbert, Wheelock, and Wilson (2004), suggests that the Monetary Control Act did not result in an immediate improvement in the efficiency with which the Fed delivers services. Gilbert, Wheelock, and Wilson (2004) find, however, that Fed offices generally became more productive during the 1990 s, with considerable convergence across offices. Nevertheless, that study also finds that as of 1999, the median Fed office could have feasibly reduced its input usage by about 30 percent without reducing output. 4

Although Gilbert, Wheelock, and Wilson (2004) find that, over time, Fed offices increased output (e.g., checks processed) for given amounts of input (e.g., labor and processing equipment), this increase in productivity does not imply that Fed offices necessarily became more efficient; that is, they did not necessarily move closer to the production frontier. The extent to which an office is (in)efficient is reflected in the difference between the amount of output the office actually produces and the amount it could feasibly produce using available technology. Technological improvement implies an increase in the amount of output that can be produced for given amounts of input, i.e., a shift in the production frontier. Therefore, because of technological improvement, an office could become more productive, i.e., produce more output using given amounts of input, without becoming more efficient, i.e., moving closer to the production frontier. In this article, we control for changes in (estimated) technology to determine whether Fed offices generally became more efficient in terms of feasible production over time. At the same time, we use newly developed techniques for estimating efficiency and a longer sample period than Gilbert, Wheelock, and Wilson (2004).

\footnotetext{
common efficiency measures include cost efficiency, which examines the extent to which a firm minimizes total cost, given input prices and output quantities, and profit efficiency, which examines the extent to which a firm maximizes profit

4 Estimates of average inefficiency obtained by this and other studies of Fed check production range from less than 5 percent to 35 percent depending on the type of efficiency studied, estimator used, and sample period. Such estimates are in line with estimates of inefficiency for private sector firms, including commercial banks. See Berger and Humphrey (1997) for a survey of research examining inefficiency among private sector firms.
} 


\section{Table 1}

\section{Definitions and Measurement of Inputs}

1. Personnel: number of employee hours

2. Materials, Software, Equipment, and Support

Expenditures are deflated by the following price measures to obtain physical units, which are then combined using a Tornquist index:

Materials: GDP implicit price deflator (seasonally adjusted, $1996=100$ )

Software: Private nonresidential fixed investment deflator for software (seasonally adjusted, $1996=100$ )

Equipment:

For 1979-89: PPI for check-handling machines (June $1985=100$ )

For 1990-2003: PPI for the net output of office machinery manufacturing (not seasonally adjusted, June $1985=100)$

Support: GDP implicit price deflator (seasonally adjusted, $1996=100$ )

3. Transit (Shipping, Travel, Communications, and Data Communications Support)

Expenditures are deflated by the following price measures to obtain physical units, which are then combined using a Tornquist index:

Shipping and Travel: Private nonresidential fixed investment deflator for aircraft (seasonally adjusted, $1996=100)$

Communications and Data Communications Support: Private nonresidential fixed investment deflator for communications equipment (seasonally adjusted, $1996=100$ )

4. Facilities: Expenditures are deflated by the following price index: "Historical Cost Index" from Means Square Foot Costs Data 2000 (R.S. Means Company: Kingston, MA, pp. 436-42). Data are January values.

SOURCE: Federal Reserve Planning and Control System documents unless otherwise noted.

\section{Federal Reserve Check Processing}

The clearing of checks involves receiving checks from depositing banks (defined broadly to include all depository institutions), sorting them, crediting the accounts of depositing banks, and delivering the checks to the banks upon which they are drawn. Such "forward items" processing is the main source of revenue and total cost for Fed check operations. Some Fed offices process federal government checks and postal money orders, as well as commercial checks. Fed offices also process "return items" (which include checks returned because of insufficient funds) and "adjustment items" (which arise because of processing or other errors) and provide various electronic check services, such as imaging and truncation. Following other studies, we focus on the forward processing of commercial and federal government checks.

The methods we use permit estimation of the efficiency of check offices with multiple outputs. In addition to the number of forward items processed, we also treat the number of endpoints served by a
Fed check office as an output. An endpoint is an office of a depository institution to which the Fed delivers checks; hence, the number of endpoints is a measure of the level of service provided by a Fed office. Presumably, an office serving many endpoints provides a higher level of service than an office serving few endpoints. In this sense, check processing is analogous to the delivery of mail by a post office. The output of a post office is not simply the number of items it delivers, but also the number of addresses to which it delivers mail. A post office that delivers mail to a single address provides a lower level of service than an office that delivers the same quantity of mail to several addresses. ${ }^{5}$

Federal Reserve offices incur a variety of costs associated with the processing of checks. Estimation of efficiency using statistical methods requires the specification of a model of the production process with a limited number of inputs. We follow Gilbert,

\footnotetext{
5 Gilbert, Wheelock, and Wilson (2004) provide statistical evidence that the number of endpoints should be treated as a distinct, second output of check processing.
} 


\section{Table 2}

\section{Summary Statistics for Inputs and Outputs}

\begin{tabular}{|c|c|c|c|c|c|}
\hline & Mean & Median & Variance & Minimum & Maximum \\
\hline \multicolumn{6}{|l|}{ 1980:Q1-1994:Q4 } \\
\hline Checks (1000s) & 80,734 & 69,985 & $2.25 \mathrm{e} 9$ & 10,413 & 265,631 \\
\hline Endpoints & 430 & 366 & $9.33 \mathrm{e} 4$ & 32 & 1,686 \\
\hline Personnel (hours) & 35,686 & 28,741 & $6.63 \mathrm{e} 8$ & 4,905 & 201,529 \\
\hline Material, etc. & 1,899 & 1,567 & $1.30 \mathrm{e} 6$ & 155 & 7,403 \\
\hline Transit & 1,509 & 1,328 & $8.14 \mathrm{e} 5$ & 148 & 6,678 \\
\hline Facilities & 716 & 485 & $3.62 \mathrm{e} 5$ & 63 & 4,438 \\
\hline \multicolumn{6}{|l|}{ 1995:Q1-2000:Q4 } \\
\hline Checks (1000s) & 93,267 & 85,324 & $2.19 \mathrm{e} 9$ & 17,205 & 280,006 \\
\hline Endpoints & 351 & 339 & $4.21 \mathrm{e} 4$ & 32 & 1,262 \\
\hline Personnel (hours) & 30,827 & 26,825 & $3.41 \mathrm{e} 8$ & 5,478 & 111,204 \\
\hline Material, etc. & 2,008 & 1,658 & $1.82 \mathrm{e} 6$ & 373 & 10,630 \\
\hline Transit & 484 & 372 & $1.26 \mathrm{e} 5$ & 20 & 2,124 \\
\hline Facilities & 741 & 561 & $2.94 \mathrm{e} 5$ & 129 & 3,991 \\
\hline \multicolumn{6}{|l|}{ 2001:Q1-2003:Q3 } \\
\hline Checks (1000s) & 104,579 & 96,559 & $2.70 \mathrm{e} 9$ & 18,253 & 292,891 \\
\hline Endpoints & 314 & 290 & $2.85 \mathrm{e} 4$ & 92 & 955 \\
\hline Personnel (hours) & 27,931 & 22,930 & $2.57 \mathrm{e} 8$ & 4,357 & 111,497 \\
\hline Material, etc. & 2,597 & 2,303 & $2.11 \mathrm{e} 6$ & 424 & 9,853 \\
\hline Transit & 516 & 403 & $1.14 \mathrm{e} 5$ & 111 & 1,805 \\
\hline Facilities & 935 & 780 & $3.98 \mathrm{e} 5$ & 160 & 3,870 \\
\hline
\end{tabular}

Wheelock, and Wilson (2004), which in turn follows Bauer and Hancock (1993) and Bauer and Ferrier (1996), in defining four distinct categories of inputs used in the processing of forward items and serving endpoints: (i) personnel; (ii) materials, software, equipment, and support; (iii) transit; and (iv) facilities. Our model requires estimates of the physical quantities used of each input rather than total expenditures. Table 1 describes how we construct each of the four inputs using expense data for each Fed check facility; Table 2 provides summary statistics for the four inputs and two outputs. Our data include quarterly observations spanning 1980:Q1-2003:Q3 for each Fed office that operated at any time during this period. Because of changes in the Fed's cost accounting system, there are discontinuities in the data at the ends of 1994 and 2000. Hence, we report summary statistics for 1980:Q1 - 1994:Q4, 1995:Q1 2000:Q4, and 2001:Q1-2003:Q3 separately.

\section{ESTIMATING EFFICIENCY}

Statistical estimation of efficiency requires a model relating production inputs and outputs. Many studies estimate translog cost or profit functions that include a two-sided random noise term and a one-sided random inefficiency term. The translog functional form has been shown to misspecify cost relationships for several types of firms, however, including commercial banks (see, e.g., McAllister and McManus, 1993; Wheelock and Wilson, 2001). Instead of estimating translog or other parametric functions, some studies use nonparametric methods to estimate efficiency. An estimate of inefficiency for an individual office consists of a measure comparing that office with an estimate of best practice. Common nonparametric estimators of the production frontier are the data envelopment analysis (DEA) and the free disposal hull (FDH) estimators. Nonparametric estimators do not require specification 


\section{Figure 1}

\section{True and Estimated Production Frontier}

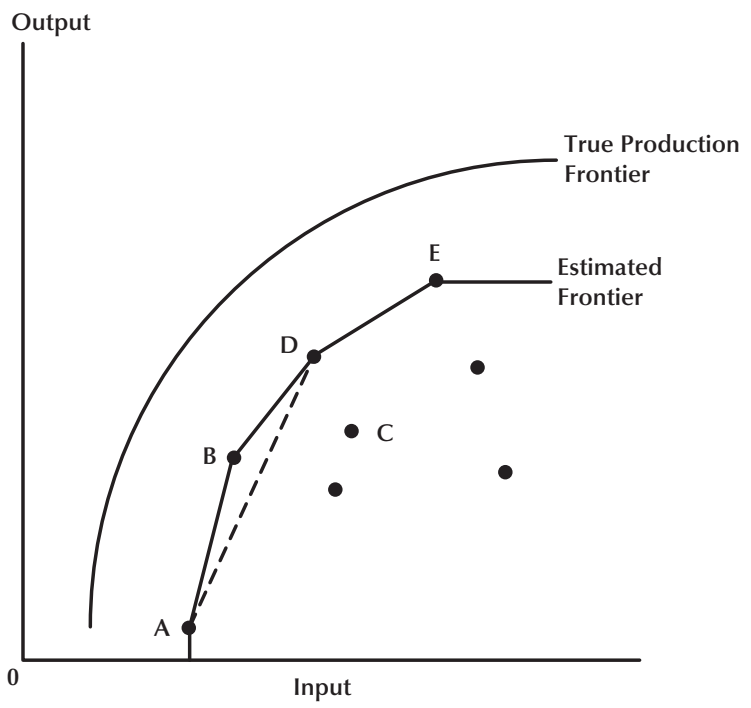

of a particular functional relationship between production inputs and outputs. DEA and FDH do impose certain assumptions about the shape of the production surface, or technology, however, and applications often require very large data sets to obtain meaningful efficiency estimates. DEA and FDH are also highly sensitive to extreme observations and noise in the data. ${ }^{6}$

The order- $m$ estimator proposed by Cazals, Florens, and Simar (2002), by contrast, is robust to extreme values and noise. Further, the order- $m$ estimator imposes fewer assumptions on the shape of the production surface than DEA. Perhaps most importantly, for large numbers of inputs and outputs, the order- $m$ estimator requires far less data to obtain meaningful estimates of inefficiency than do frontier estimators, such as DEA or FDH. This section presents non-technical descriptions of DEA and order- $m$ estimation. Readers interested in detailed treatments are referred to Cazals, Florens, and Simar (2002) and Wheelock and Wilson (2003).

\section{Data Envelopment Analysis}

DEA uses observations on outputs and inputs of decisionmaking units (e.g., firms or, in our application, Federal Reserve check offices) to estimate

\footnotetext{
6 See Simar and Wilson (2000) and Kneip, Simar, and Wilson (2003) for discussion of the statistical properties of FDH and DEA estimators.
}

\section{Figure 2}

\section{Estimating Efficiency}

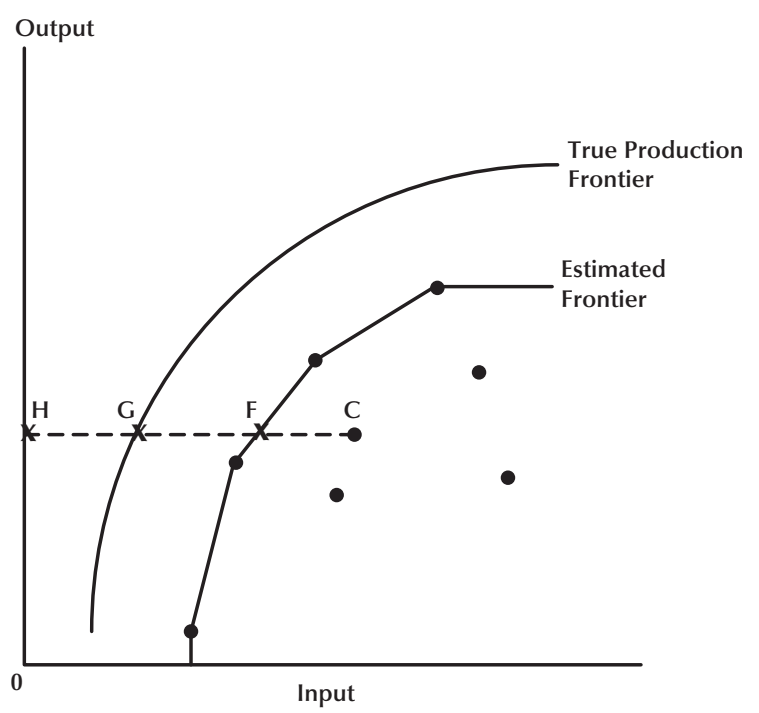

the most productive combinations of outputs and inputs that are technically feasible, i.e., "efficient" combinations. The inefficiency of specific firms can be estimated by comparing their actual input/output combinations with efficient combinations. The more input a firm uses to produce given quantities of output (or, equivalently, the less output a firm produces from given quantities of inputs) relative to an efficient combination, the less efficient is the firm.

Figure 1 illustrates the technique for estimating the relationship between input and output for a production process that has one input and one output. The dots represent observed levels of input and output for eight firms. If we had complete information about the minimum level of input that firms require to produce a given level of output, we could trace out the true production frontier. We could then assess the degree to which a particular firm is inefficient by measuring its distance from the frontier. Given the amount of output produced, the inefficiency of a firm reflects the reduction in the input the firm would use if it were on the frontier. Alternatively, we could measure inefficiency in terms of the increase in output a firm could produce, for a given level of input, if the firm operated on the frontier.

Lacking complete information, we must assess the efficiency of firms from observations of the inputs and outputs of actual firms. We trace out the estimated frontier in Figure 1 by connecting the dots for firms A, B, D, and E. The only constraint we 


\section{Figure 3}

\section{Order-m Efficiency}

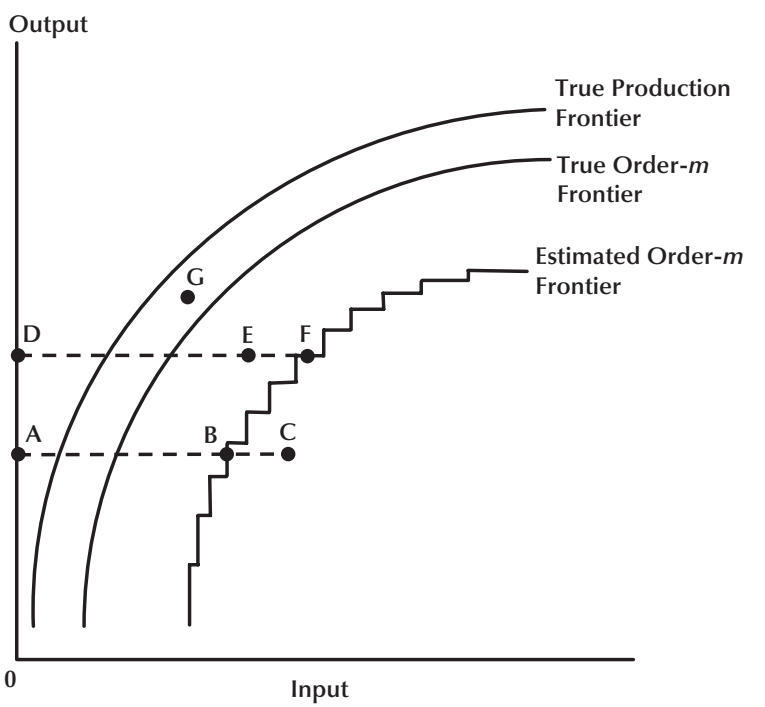

impose on the shape of the estimated frontier is that it does not include firms like C. More precisely, we assume the frontier is convex, i.e., that any two points on or under the frontier can be connected by a line segment that never passes above the frontier. Firm $\mathrm{C}$ is inefficient relative to the observed frontier in the sense that it could feasibly produce the same level of output using less input (or, equivalently, produce more output from the same amount of input).

We illustrate the DEA efficiency measure in Figure 2. Consider the firm with the amounts of input and output labeled $\mathrm{C}$. That firm produces an amount of output equal to the vertical distance $\mathrm{OH}$ using an amount of input equal to the horizontal distance HC. If firm C were more efficient, it could use less input to produce $\mathrm{OH}$ output (or, equivalently, use $\mathrm{HC}$ input to produce more output than $\mathrm{OH}$ ). The extent to which firm $C$ could improve is reflected in the difference in the amount of input used by firm $\mathrm{C}$ and the horizontal distance GC. Because we do not know the location of the true frontier, however, we estimate the potential improvement in efficiency of firm $\mathrm{C}$ as the difference between $\mathrm{HC}$ and the amount of input that a firm (perhaps hypothetical) located on the estimated frontier and producing the same amount of output as firm $\mathrm{C}$ would use (distance FC). To measure inefficiency, we divide the distance $\mathrm{HC}$ by the distance HF. This ratio is greater than 1.0 for all firms that lie off the estimated frontier; and the larger this ratio, the less efficient the firm. ${ }^{7}$

Estimation of the efficient frontier requires certain assumptions. Standard assumptions, which we impose here, are that (i) the production set is convex and closed; (ii) all production requires the use of some inputs, and both inputs and outputs are strongly disposable; (iii) the observed set of inputs and outputs for check processing offices results from independent draws from a probability density function with bounded support over the production set; (iv) this density is strictly positive for all points along the frontier; (v) starting from any point along the frontier, the density is continuous in any direction toward the interior of the production set; and (vi) the true frontier is smooth. Together, these assumptions define the data-generating process that produces sample observations, and permit statistical estimation and inference about the unobserved technology as well as the unobserved input distance function. 8

\section{Order-m Estimators}

As an alternative to nonparametric estimators of the production frontier, such as DEA, Cazals, Florens, and Simar (2002) propose estimators based on the expected minimum input frontier of order $m .{ }^{9}$ Order- $m$ estimators do not impose the assumption that the production set is convex, and in addition they permit noise (with zero expected value) in input measures. Note that DEA estimates of the production frontier can be severely distorted by extreme values. Individual observations have much less influence on order- $m$ estimation. Further, for given numbers of inputs and outputs, the order- $m$ estimator requires far less data to produce meaningful efficiency estimates than DEA or FDH estimators. ${ }^{10}$

Consider again a production process involving firms that use a single input to produce a single output. In this case, the expected minimum input frontier of order $m$ is simple to estimate: (i) For each

\footnotetext{
7 This measure of productivity is the Shephard input distance function. See Shephard (1970).

${ }^{8}$ See Simar and Wilson (2000) for more detailed discussion of these assumptions and the DEA estimator.

9 Order- $m$ estimators can also be applied in the output direction, i.e. to estimate the expected maximum output frontier of order $m$.

${ }^{10}$ Specifically, order- $m$ estimators converge to their population counterparts at a rate equal to the square root of the sample size, which is far faster than the convergence rates of DEA and FDH estimators in our application. See Wheelock and Wilson (2003).
} 


\section{Figure 4}

\section{DEA Efficiency}

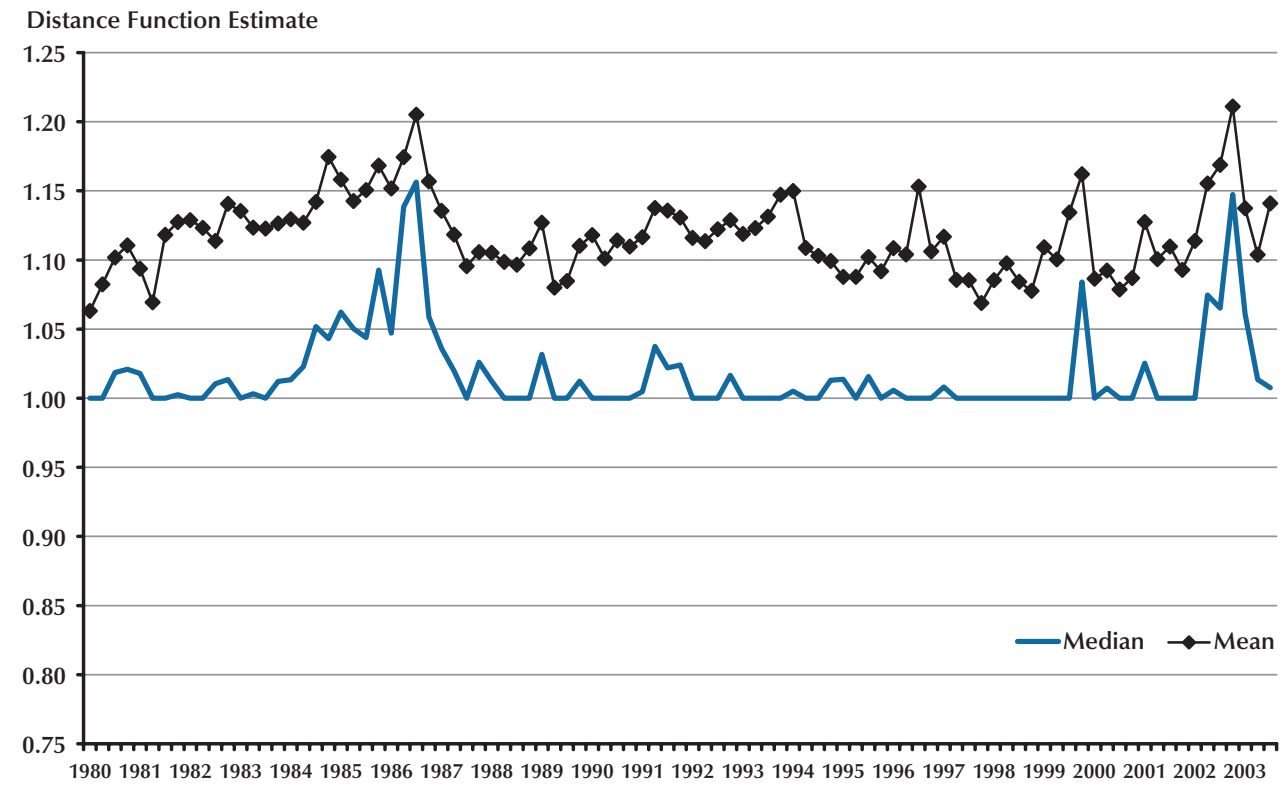

firm, identify all other firms that produce at least as much output as that firm. (ii) Draw $m$ times, independently, with replacement, from this set of firms, identifying the firm among the $m$ draws that uses the minimum amount of input. (iii) Repeat step (ii) $k$ times. (iv) Compute the mean input usage of the $k$ firms identified in the sampling of steps (ii) and (iii). The estimated expected minimum input frontier constitutes the means computed for each sample observation. ${ }^{11}$ The estimated frontier will lie below and to the right of the true order- $m$ frontier, which itself will lie below and to the right of the true production frontier, as illustrated in Figure 3. ${ }^{12}$

For any given firm, an estimate of order- $m$ inefficiency is obtained by computing the distance from the firm to the estimated order- $m$ frontier, as illustrated in Figure 3. A hypothetical expected minimum input frontier of order $m$ is traced out by the various line segments as shown. For firm C, inefficiency is estimated by the ratio $\mathrm{AC} / \mathrm{AB} .{ }^{13}$ In other words, based

${ }^{11}$ The choice of $m$ and $k$ will depend on the particular application at hand, as discussed later.

${ }^{12}$ The order- $m$ frontier need not be convex, as illustrated by the "stairstep" shape of the estimated frontier in Figure 3.

${ }^{13}$ As with DEA, this distance corresponds to the Shephard (1970) input distance function. on computation of the order- $m$ frontier, firm $C$ uses $100[(\mathrm{AC} / \mathrm{AB})-1]$ percent more input than the minimum amount the firm could be expected to use.

Note that some firms might use less input than the expected minimum amount, as illustrated by firm E in Figure 3. For firm E, "inefficiency" is estimated by the ratio DE/DF, which is less than 1 . This firm uses 100(DE/DF) percent of the expected minimum amount of input, based on order- $m$ sampling of all firms that produce as much output as firm E. Finally, note that some firms, e.g., firm G, might lie above the true order $-m$ frontier. ${ }^{14}$

\section{ESTIMATION RESULTS}

We present efficiency estimates based on both the DEA and order- $m$ estimators. For each quarter, we use DEA to estimate the production frontier from observations on all offices producing positive amounts of both outputs (forward check items and

${ }^{14}$ In the case of multiple outputs, the $m$ firms are drawn from the set of firms that produce at least as much of all outputs as the firm of interest. When there are multiple inputs, the minimum input usage among $m$ firms is determined by a minimax algorithm. This minimum converges to the FDH estimate of the production frontier as $m$ approaches infinity. FDH differs from DEA only in that it does not assume the production frontier to be convex. For a mathematically precise description of the order- $m$ frontier in the case of multiple inputs and/or outputs, see Cazals, Florens, and Simar (2002) or Wheelock and Wilson (2003). 
endpoints). ${ }^{15}$ We then estimate the inefficiency of each office using the DEA distance function estimator described here previously.

Our approach differs from that of Gilbert, Wheelock, and Wilson (2004). Because we estimate a production frontier for every period, we obtain efficiency estimates for every office in every quarter of our sample. By contrast, Gilbert, Wheelock, and Wilson (2004) pool observations on Fed offices over time and estimate a single frontier. Consequently, they obtain efficiency estimates only for the final period of their sample (1999:Q4). Gilbert, Wheelock, and Wilson (2004) do produce distance function estimates for every office in every period relative to the single frontier, however, and changes in those estimates over time reflect changes in the productivity of individual offices. Moreover, because pooling effectively increases their sample size, the estimate of the production frontier for the final period obtained by Gilbert, Wheelock, and Wilson (2004) is probably more reliable than our quarterly estimates.

Figure 4 plots the mean and median efficiency (distance function) estimates across all offices in each quarter. DEA efficiency estimates are greater than or equal to 1 , with an estimate of 1 implying that an office is fully efficient. Larger estimates imply lower efficiency.

On average, Fed offices appear to have become less efficient between 1980 and 1982, when the pricing requirements imposed by the Monetary Control Act were fully implemented. Efficiency continued to worsen to a peak in the third quarter of 1986. Mean and median efficiency then improved to approximately their pre-1982 levels. From 1987 to 2003, mean inefficiency ranged between 5 and 20 percent in all but one quarter. That is, on average, Fed offices used 5 to 20 percent more input to produce given amounts of output than DEA estimation indicates was technically feasible. Thus, our estimates suggest that Fed offices became less efficient when the Monetary Control Act was first implemented, but by the late 1980s inefficiency had stabilized. We find little evidence to suggest that the Monetary Control Act improved average efficiency in the long run, though median inefficiency was low throughout the late 1980s and 1990s before spiking in 1999 and again in 2002-03. Indeed, our estimates indicate

${ }^{15}$ Between 43 and 48 offices are used to estimate the frontier in each quarter. A few observations were dropped because of missing data. that in several quarters more than half of Fed offices were fully efficient. ${ }^{16}$

As noted previously, there are reasons to be suspicious of DEA efficiency estimates, particularly in cases where the number of observations used to estimate the efficient frontier is small. The order- $m$ class of estimators provides another way of looking at efficiency that is less sensitive to extreme-value observations and small samples. ${ }^{17}$

Figures 5 and 6 plot quarterly mean and median values of order- $m$ distance estimates across all check offices for four values of $m$. As with our DEA estimation, for each value of $m$, we estimate a distinct order- $m$ frontier for each quarter using observations on check offices for only that quarter. Recall that the order- $m$ distance estimate for any given office in any period is obtained by comparing the actual input usage of that office with the expected minimum input usage of the office, where the expected minimum is obtained by drawing $k$ samples of $m$ offices that produce at least as much output as the office of interest. The minimum input usage among the $m$ offices in each of the $k$ samplings is recorded, with the expected minimum input usage for the office of interest calculated as the mean of the minimums observed in each of the $k$ samplings. We set $k$ equal to 200, which, by the law of large numbers, should be sufficient to obtain accurate estimates of the true mean without being computationally prohibitive.

The order- $m$ distance estimate for each check office reflects the extent to which that office uses a different amount of input to produce its output level from the expected minimum input amount, as determined by the sampling algorithm described previ-

\footnotetext{
${ }^{16}$ Gilbert, Wheelock, and Wilson (2004) find general improvement in the productivity of Fed check offices from the late 1980s through the 1990s. Our results, in combination with those reported by Gilbert, Wheelock, and Wilson (2004) suggest that the technology of Fed check processing was improving.

${ }^{17}$ Another reason to be suspicious of our DEA efficiency estimates is that they appear to be heavily dependent on the assumption that the production frontier is convex. We also used the FDH estimator, which relaxes the assumption of convexity but is otherwise identical to DEA, to estimate efficiency. Using FDH, we find that average inefficiency of Fed offices ranged from 0 to 4 percent throughout 1980-2003 and that the median inefficiency across Fed offices was always zero, i.e., that at least half of Fed offices were fully efficient in every quarter (typically, some 90 percent of offices were found to be fully efficient). Hence, our DEA estimates are strongly affected by the convexity assumption. This may not be a bad assumption, but one might not want to draw strong conclusions based on results that are so heavily influenced by a single assumption.
} 


\section{Figure 5}

\section{Mean Order-m Efficiency}

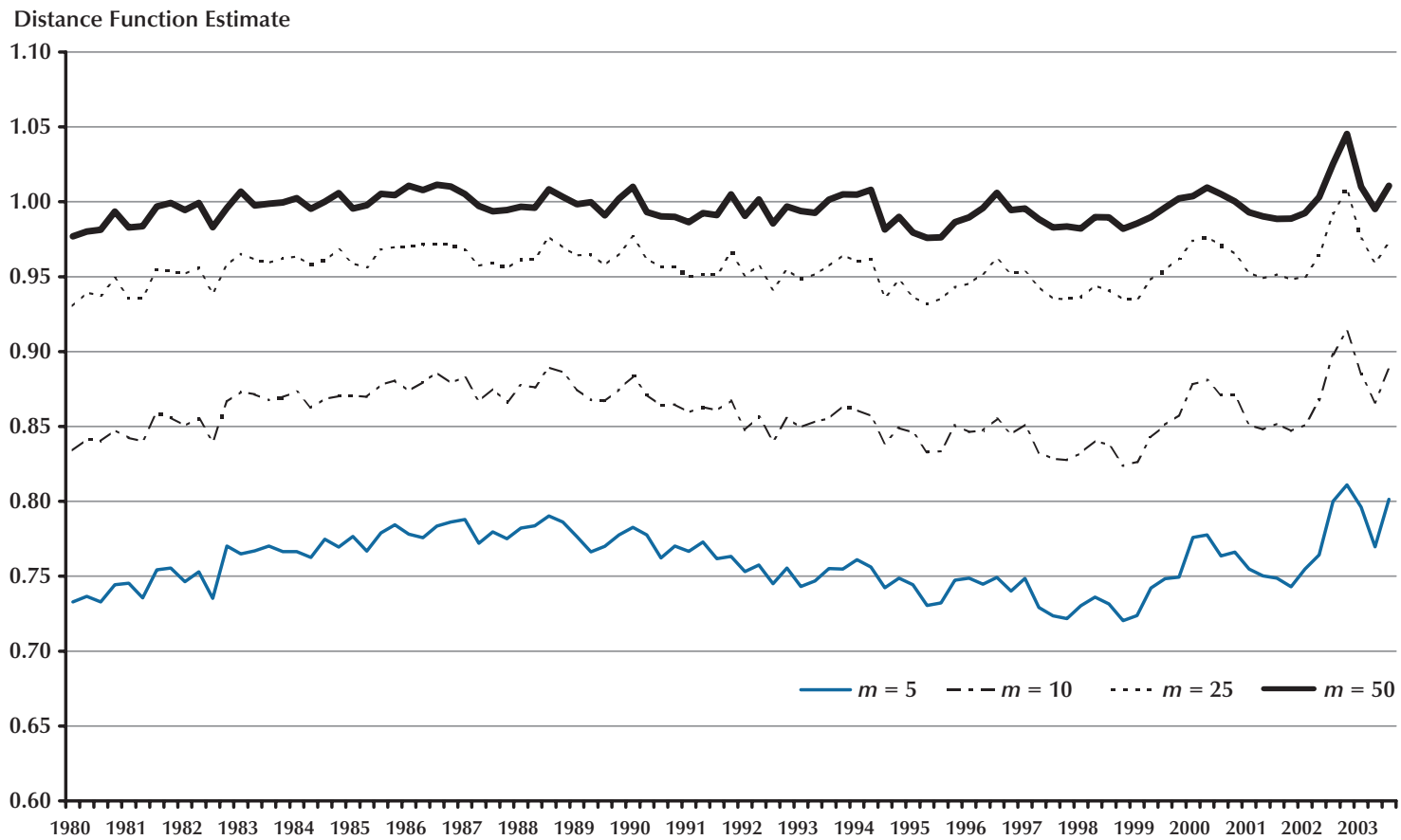

\section{Figure 6}

\section{Median Order- $\boldsymbol{m}$ Efficiency}

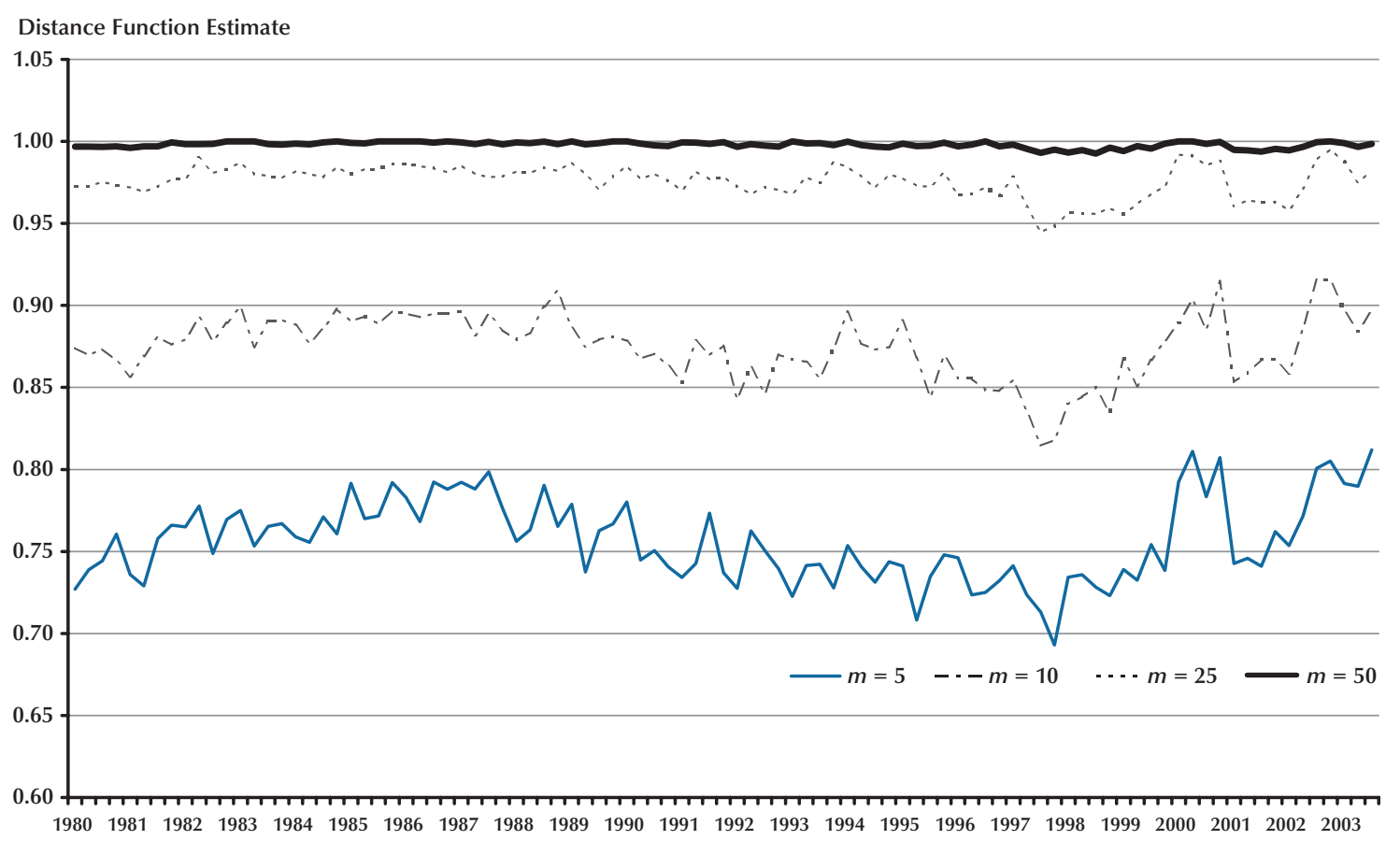




\section{Figure 7}

\section{Order- $m$ Efficiency Estimates, $m=5$ vs. $m=10$}

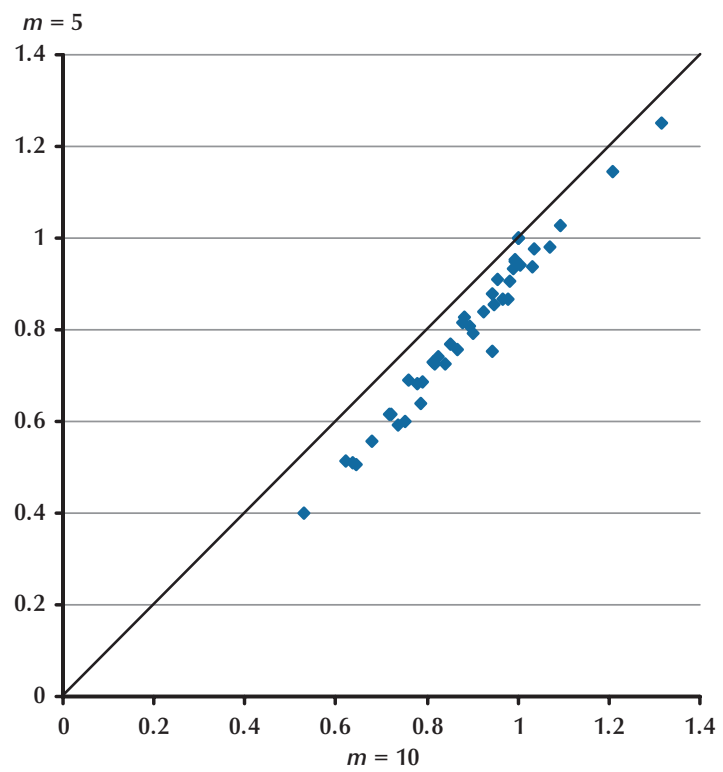

\section{Figure 8}

\section{Order- $m$ Efficiency Estimates,} $m=10$ vs. $m=25$

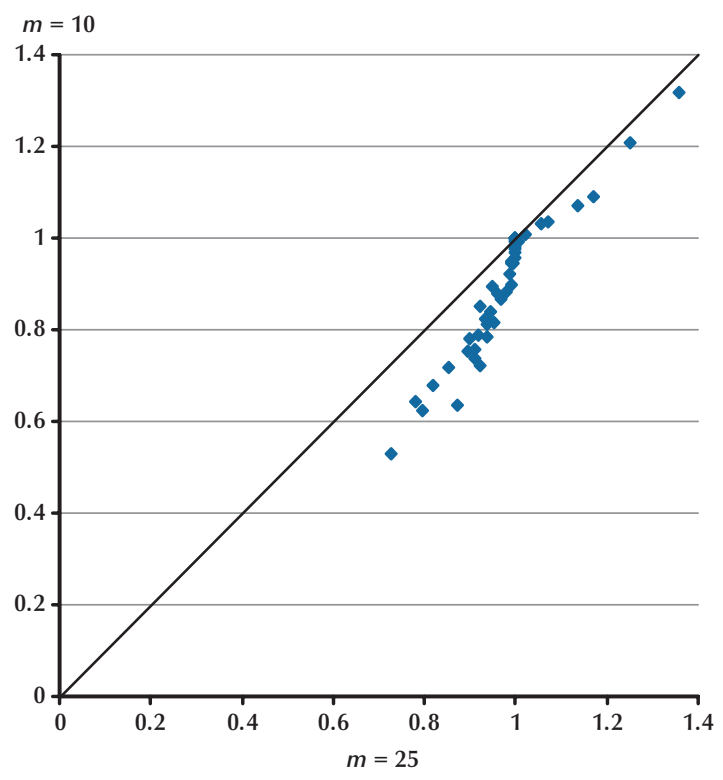

\section{Figure 9}

\section{Order- $m$ Efficiency Estimates, $m=25$ vs. $\boldsymbol{m}=\mathbf{5 0}$}

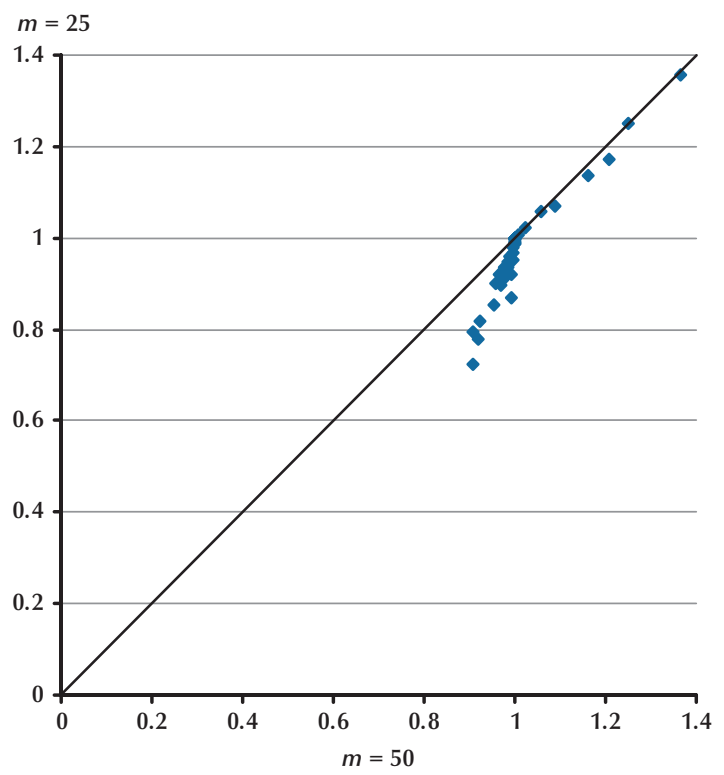

ously. A distance estimate larger than 1.0 indicates that the office uses more than the expected minimum, whereas a distance estimate less than 1.0 indicates that the office uses less than the expected minimum.

In general, the order- $m$ inefficiency estimate for an office will be larger for larger values of $m$. Because the offices in the sample drawn to compute the order- $m$ frontier produce at least as much output as the office in question, and because offices that produce more output typically use more input, the minimum input usage among $m$ offices will tend to be smaller, the larger the number of offices sampled (i.e., the larger the value of $m$ ). Hence, the expected minimum input usage for any given office will generally be smaller, and the less efficient the office will appear to be, the larger the value of $m$. As Cazals, Florens, and Simar (2002, p. 7) note, the choice of $m$ is arbitrary, but "a few values of $m$ could be used to guide the manager of the production unit to evaluate its own performance" (p. 7). Here we are interested in the performance of Fed check offices in general, not specific offices, and the behavior of mean and median efficiency of check offices over time is 


\section{Figure 10}

\section{Order- $m$ Efficiency, $m=5$}

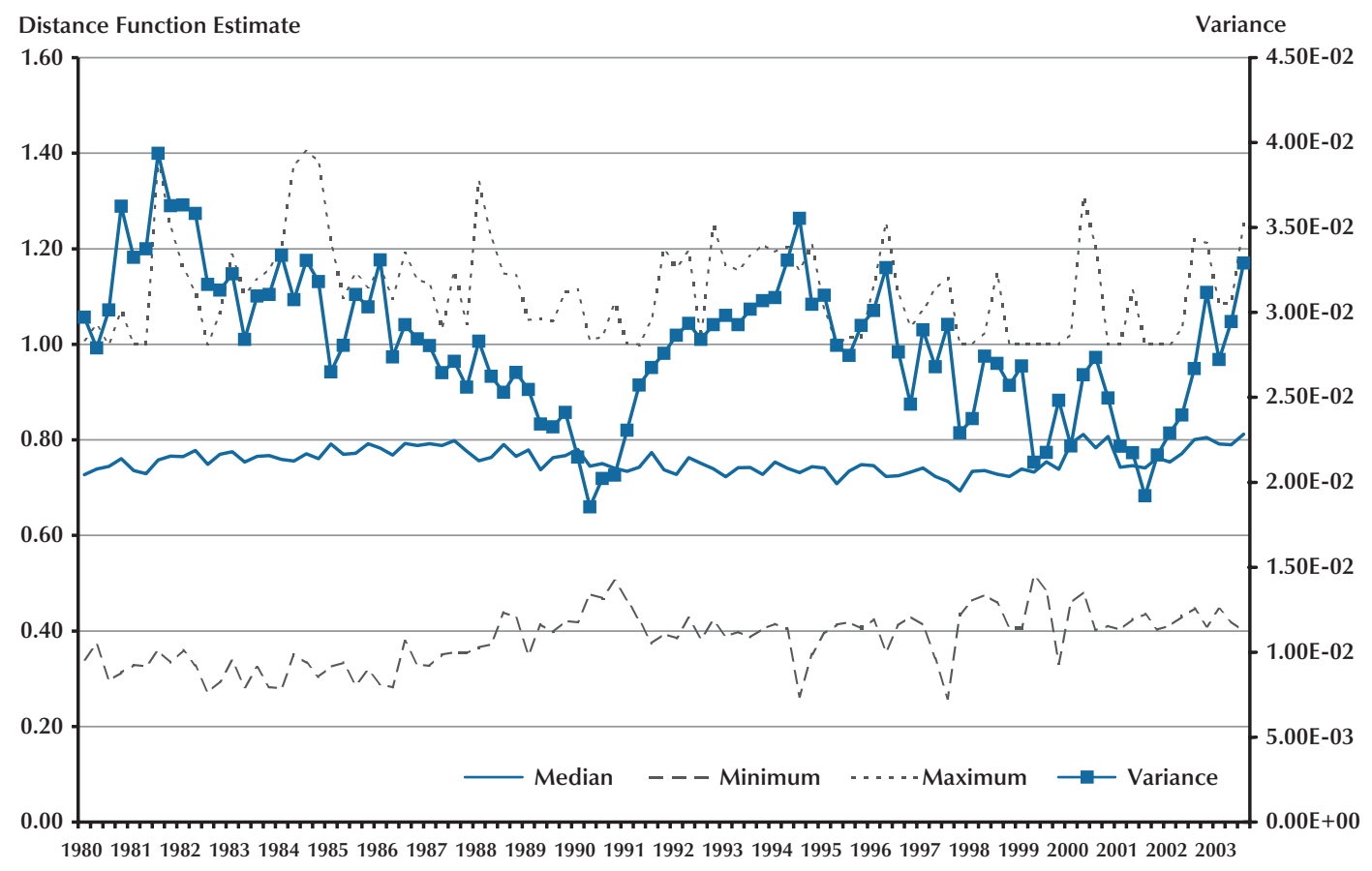

largely invariant to the choice of $m .{ }^{18}$ Moreover, as Figures 7 to 9 illustrate for 2003:Q3, efficiency estimates for individual offices using different values of $m$ are highly correlated.

Although distance estimates and, hence, estimated order- $m$ efficiency, vary with the value of $m$ chosen, the trends in the mean and median values are similar across the four values of $m$-first increasing from 1980 to around 1987, then declining through about 1998, and finally rising through 2003. The changes in the trends are rather small, however, relative to the quarterly variability in the mean and median values, suggesting that the changes might not be statistically significant.

Consistent with the DEA efficiency estimates, Fed offices seem to have become somewhat less order- $m$ efficient when the pricing regime was first

${ }^{18}$ Cazals, Florens, and Simar (2002) show that the order- $m$ frontier converges to the FDH frontier as $m$ approaches infinity. In our application, median order- $m$ efficiency is very close to 1 in every period for $m=50$, consistent with our finding that approximately 90 percent of all Fed offices are located on the FDH frontier in every period. The location of a high percentage of observations on the FDH (and DEA) frontier reflects a "curse of dimensionality" that plagues nonparametric frontier estimation when the combined number of inputs and outputs is high relative to the number of observations. introduced. For example, for $m=5$, the median order- $m$ distance estimate rises from approximately 0.73 in 1980 to 0.80 at its peak in 1987. In other words, in 1980, the input usage of the median office was 73 percent of the expected minimum amount, whereas in 1987, the input usage of the median office was 80 percent of the expected minimum amount. Order- $m$ efficiency began to improve in the late 1980s, however, and continued to improve during much of the 1990s, a pattern consistent with the estimates of productivity obtained by Gilbert, Wheelock, and Wilson (2004). Mean and median estimates of order- $m$ efficiency began to worsen around 1999, and also became somewhat more variable.

Mean and median efficiency estimates do not, of course, tell the whole story. Figure 10 plots the quarterly minimum, maximum, and median order- $m$ efficiency estimates alongside the variance across Fed offices for $m=5$ (plots for other values of $m$ look similar). The plot reveals considerable variation over time in the minimum and, especially, maximum inefficiency estimates. In general, the variation in efficiency estimates across offices declined after the pricing regime was implemented in 1982, even 
as mean and median inefficiency worsened through about 1987. After 1990, however, efficiency estimates became more dispersed until about 1994. Since then, dispersion has varied considerably from quarter to quarter.

\section{DISCUSSION}

We have examined the technical efficiency of Fed check offices over a long period that involved numerous environmental changes. The major environmental change of the early 1980 s was the implementation of the pricing requirements of the Monetary Control Act of 1980. Both our DEA and order- $m$ estimates suggest that, if anything, Fed offices became less efficient on average after full implementation of pricing in 1982. Efficiency had begun to improve by the late 1980s, however, and Fed offices generally became more efficient during the 1990s.

Federal Reserve check processing volume has been declining since 1999-a trend that is expected to continue, especially with enactment of the Check Clearing for the 21 st Century Act. Our results indicate that the input-technical efficiency of Fed offices declined on average after 1999, with increased dispersion across offices. Because it is difficult and costly to reduce input amounts quickly, one would expect to observe a decrease in the efficiency of an office experiencing a sharp drop in check processing volume. Hence, one should be cautious about drawing strong conclusions about performance from short-run fluctuations in estimated efficiency.

While our results provide information about changes in the technical efficiency of the average (and median) Fed check office over time, it is important to note that we do not examine other types of efficiency or performance measures. For example, a measure of "overall" efficiency would capture both technical efficiency and allocative efficiencywhich takes into consideration the feasibility of substituting among input types in response to shifts in relative input prices. One could also examine scale efficiency, which reflects the extent to which offices produce an efficient level of output. ${ }^{19}$

Further, while we have extended the standard model used to examine the efficiency of check office production by including the number of endpoints to which a check office delivers checks as a

\footnotetext{
${ }^{19}$ Gilbert, Wheelock, and Wilson (2004) examine scale efficiency and find no evidence that, as of 1999, any Fed office produced an inefficient level of output.
}

second type of output, our model cannot account for all differences in the operating environments or production of different check offices. Hence, as is the case with any empirical study of efficiency, differences in estimated efficiency across offices necessarily confound true differences in inefficiency that might be within the ability of managers to control with factors that are largely beyond control. For example, although we account for differences in the number of endpoints across offices, we do not control for differences in the geographic dispersion of endpoints served by Fed offices that could explain differences in their use of transportation input. ${ }^{20}$ Nevertheless, while an examination of the causes of observed differences in estimated efficiency across offices is beyond the scope of the present study, the methodology described and illustrated in this article provides a framework for identifying differences that could help guide managers in their search for ways to control costs.

\section{REFERENCES}

Bauer, Paul W. and Ferrier, Gary D. "Scale Economies, Cost Efficiencies, and Technological Change in Federal Reserve Payments Processing." Journal of Money, Credit, and Banking, November 1996, 28(4), pp. 1004-39.

Bauer, Paul W. and Hancock, Diana. "The Efficiency of the Federal Reserve in Providing Check Processing Services." Journal of Banking and Finance, April 1993, 17(2-3), pp. 287-311.

Berger, Allen N. and Humphrey, David B. "Efficiency of Financial Institutions: International Survey and Directions for Future Research." European Journal of Operations Research, April 1997, 98(2), pp. 175-212.

Board of Governors of the Federal Reserve System. Annual Report, 2000.

Board of Governors of the Federal Reserve System. Annual Report, 2002.

Cazals, Catherine; Florens, Jean-Pierre and Simar, Léopold. "Nonparametric Frontier Estimation: A Robust Approach." Journal of Econometrics, January 2002, 106(1), pp. 1-25.

Gerdes, Geoffrey R. and Walton, Jack K. "The Use of Checks

\footnotetext{
${ }^{20}$ Bauer and Hancock (1993) find that cost inefficiency of Fed check production was closely related to the geographic density of endpoints over their sample period.
} 
and Other Noncash Payment Instruments in the United States." Federal Reserve Bulletin, August 2002, 88(8), pp. 360-74.

Gilbert, R. Alton; Wheelock, David C. and Wilson, Paul W. "New Evidence on the Fed's Productivity in Providing Payments Services." Journal of Banking and Finance, September 2004, 28(9), pp. 2175-90.

Kneip, Alois; Simar, Léopold and Wilson, Paul W. "Asymptotics for DEA Estimators in Non-parametric Frontier Models." Discussion Paper No. 0317, Institut de Statistique, Université Catholique de Louvain, Louvainla-Neuve, Belgium, 2003.

McAllister, Patrick H. and McManus, Douglas A. "Resolving the Scale Efficiency Puzzle in Banking." Journal of Banking and Finance, April 1993, 17(2-3), pp. 389-405.

Shephard, Ronald W. Theory of Cost and Production Functions. Princeton: Princeton University Press, 1970.

Simar, Léopold and Wilson, Paul W. "Statistical Inference in Nonparametric Frontier Models: The State of the Art." Journal of Productivity Analysis, January 2000, 13(1), pp. 49-78.

Wheelock, David C. and Wilson, Paul W. "New Evidence on Returns to Scale and Product Mix Among U.S. Commercial Banks." Journal of Monetary Economics, June 2001, 47(3), pp. 653-74.

Wheelock, David C. and Wilson, Paul W. "Robust Nonparametric Estimation of Efficiency and Technical Change in U.S. Commercial Banking." Working Paper No. 2003-037A, Federal Reserve Bank of St. Louis, November 2003. 
R E V I E W 